\title{
Effect of chronic treatment with grape juice during pregnancy and nursing in central nervous system of female wistar rats
}

\begin{abstract}
This study aimed to evaluate the effect of chronic treatment with purple grape juice (Vitis labrusca L.), by free access or gavage, during the pregnancy and lactation on the behavior and parameters of oxidative stress on the central nervous system tissues of female Wistar rats. The female Wistar rats $(n=40)$ were mated, and the pregnancy was confirmed by vaginal swab. After the pregnancy was confirmed, the animals were randomly divided into 4 groups: water (free access); water (gavage); juice (free access); juice (gavage). The animals were treated with water or juice (free access or gavage). The gavage was done once a day at a dose of $7 \mu \mathrm{L} / \mathrm{g}$ of body weight. On the open field test, we observed that the grape juice was able to increase the latency time, decrease the time to rearing and lower the time and the frequency crossing. In the plus maze test, the grape juice was able to decrease the time spent in the open arm, which suggests anxiolytic characteristics to the juice. On the oxidative stress analyzes, the grape juice was capable to reduce the lipid per oxidation, however, it was not able to reduce the protein oxidation induced by the damage provoke by the gavages. Grape juice increased non-enzymatic defenses (sulfhyidryl content) in the cerebral cortex. The activity of the SOD and CAT enzymes were modulated by grape juice differently depending on the tissue evaluated. We observed that the SOD/CAT ratio also presented a different behavior in each of the tissues. We conclude that pregnancy can be an important factor to alter various parameters, on behavioral or biochemical assays. However, we found that grape juice was able to improve some parameters, reducing the stress caused by gavage in brain structures.
\end{abstract}

Volume 6 Issue 3 - 2017

\author{
Mariane Farias Wohlenberg,' Fernanda \\ De Souza Machado,' Thays Krischke \\ Schaffer,' Gabrielli Bortolato,' Jéssica \\ Pereira Marinho,' Niara Da Silva Medeiros,' \\ Alexandre Mello,' Fabiana Agostini, ${ }^{2}$ Simone \\ Gerson,' Cláudia Funchal,' Caroline Dani' \\ 'Biochemistry Laboratory, Methodist University Center IPA, \\ Brazil \\ ${ }^{2}$ Biotechnology Institute, University of Caxias do Sul (UCS),
} Brazil

Correspondence: Caroline Dani, Methodist University Center IPA, St Cel Joaquim Pedro Salgado, 80, Porto Alegre, Rio Grande do Sul, Brazil, Tel +55 5l 3316 I298,

Email caroline.dani@metodistadosul.edu.br

Received: October 25, 2017 | Published: April 05, 2017

Keywords: anxious, behavior, female wistar rats, pregnancy, purple grape juice, neuroprotection

Abbreviations: DNPH, 2,4-dinitrophenylhydrazine; HPLC, high performance liquidchromatography; TBARS, thiobarbituric acid reactive substances; SDS, sodium dodecyl sulfate; TBA, thiobarbituric acid; TCA, trichloroacetic acid; DTNB, 2-nitrobenzoic acid; SOD, superoxide dismutase; CAT, catalase; H2O2, hydrogen peroxide; SPSS, statistical package for social sciences; GPx, glutathione peroxidase; GST, glutathione-s-transferase; $\mathrm{CCl} 4$, carbon tetrachloride

\section{Introduction}

Over the years, the production of grapes in Brazil is increasing. The south of Brazil, mainly "Serra Gaucha", is the largest winegrowing region of the country, with about 40 hectares of vineyards. ${ }^{1}$ In South America, grapes of the variety Vitis labrusca L. are the most widely cultivated and its derivatives, wine and grape juices are very important to this region. Different studies showed their nutrients and their important benefits, eg, antioxidant, antimutagenic and anticancer effect. ${ }^{2-4}$ Grape juice consumption as a source of phenolic compounds has an advantage to wine, since the absence of alcohol permits grape juice to be consumed by all people, such as children, pregnant women and those suffering from certain diseases, e.g, and hepatitis. ${ }^{5}$
The consumption of some foods rich in phenolic compounds is associated with a decreased in the risk of dementia and the improvements in memory and motor function. ${ }^{6}$ Other studies also demonstrate the neuro protective effect of grape juice, acting against the oxidative damage..$^{4,7-9}$ The central nervous system has high lipid content and a high aerobic metabolic activity; these facts could contribute to the oxidative damage. In addition, the high content of iron in this tissue is essential for brain development, however this content could release iron ions and thereby lead to oxidative stress. ${ }^{10,11}$ Thus, some studies showed that the polyphenols are able to reduce the risk of stroke and neurodegenerative disorders, in the nervous system. ${ }^{12,13}$

In view of these data, however, there is not a consensus as to whether the ingestion of substances rich in polyphenols during pregnancy is beneficial. Arola-Arnal ${ }^{14}$ showed that flavonoids and grape seed metabolites were widely distributed in plasma and maternal tissues. However, the data indicated that the transport across the placenta was not efficient for these compounds. ${ }^{14}$ However, other studies have shown that the consumption of these products with antioxidant and anti-inflammatory activity can interfere with the dynamics of the fetal ductus arteriosus harming the health of the mother and offspring. ${ }^{15-17}$ 
Until now, the studies were controversial in real benefits to the intake of food rich in polyphenols during pregnancy and its influence on offspring. However, several studies showed that grape juice improves the health condition against the many different inducers of stress. In this way, this study aimed to evaluate the effect of purple grape juice (Vitis labrusca L.) consumption (free access or gavage) during the pregnancy and lactation period on behavior and oxidative stress parameters in the central nervous system tissues.

\section{Materials and methods}

\section{Reagents}

TBA was purchased from Merck (Darmstadt, Germany), and 2,4-dinitrophenylhydrazine (DNPH) was obtained from Sigma (St. Louis, USA). All other reagents were of analytical grade and purchased from local suppliers.

\section{Grape juice}

The commercial conventional purple grape juice Vitis labrusca L. variety Bordo was kindly provided by Perini Winery. The juices were from the harvest of 2013 and all from the same lot. In a previous study, we found in the phenolic composition of the juice the presence of catechin, epicatechin, hesperidin, rutin, galic acid and chlorogenic acid were evidenced. ${ }^{18}$

\section{Grape juice chemical analysis and nutritional evaluation}

All analyzes were performed in duplicate. Carbohydrates (\%), and humidity levels [ashes $(\mathrm{g} / \mathrm{L})$ and moisture $(\mathrm{g} / \mathrm{L})]$, as well as ascorbic acid ( $\mathrm{mg} \mathrm{\%}$ ) were determined according to methodologies of Association of Official Analytical Chemists. ${ }^{19}$

\section{Phenolic compounds}

The total phenolic content was measured using the modification of the Folin-Ciocalteau colorimetric method, as described by Singleton et al. ${ }^{20}$ The results were expressed as $\mathrm{mg} / \mathrm{L}$ catechin equivalent. HPLC analysis was used to quantify the presence of individual phenolic compounds. The chromatographic analyzes were a modification of the methods described by Lamuela-Raventos. ${ }^{21}$

\section{Animals}

In our study 40 Wistar rats at 90days of age, weighing approximately $200 \mathrm{~g}$ from the vivarium of the Methodist University Center IPA were put to mating. The animals had free access to water and a commercial diet containing $20.5 \%$ protein (predominantly soybean), $54 \%$ carbohydrate, $4 \%$ fat, $4.5 \%$ fiber, $7 \%$ ash and $10 \%$ moisture. The animals were kept under a $12 \mathrm{~h}$ light-dark cycle at a temperature of $22^{\circ} \mathrm{C} \pm 1^{\circ} \mathrm{C}$. The pregnancy of rats was confirmed by vaginal swab, verifying the presence or absence of sperm. All experimental procedures were performed with the approval of the Ethics Committee on Animal Use of the Methodist University Center IPA, under protocol number 15/2013.

\section{Treatment}

The animals received purple grape juice Vitis labrusca $L$. for a period of 42 days (21days gestation +21 days before weaning). The administration of the grape juice was done every day in two ways: by gavage at a concentration of $7 \mu \mathrm{L} / \mathrm{g}$ of body weight or by free access. The animals were divided into 4 groups:

i. Group 1 (Water): composed of 05 pregnant female Wistar rats at 12 weeks of age who were treated with free access to water.

ii. Group 2 (Water - gavage) consisting of 15 pregnant female Wistar rats of 12 weeks of age that were treated with water at a concentration of $7 \mu \mathrm{L} / \mathrm{g}$ of body weight.

iii. Group 3 (Grape Juice): composed of 05 pregnant female Wistar rats at 12 weeks of age who were treated with free access to red grape juice.

iv. Group 4 (Grape Juice - gavage) consisting of 15 pregnant female Wistar rats at 12 weeks of age who were treated with red grape juice at a concentration of $7 \mu \mathrm{L} / \mathrm{g}$ of body weight.

In our study, 40 Wistar rats were put to mate but only 20 rats completed the treatment. For the animals that did not complete the treatment, several causes for this interruption were observed: complication of childbirth (2); seizure (1); uterine prolapse (2); death with unidentified cause (8) and other 7 animals did not become pregnant.

After the offspring breastfeeding, females, previously pregnant, were euthanized by decapitation. The cerebral cortex, hippocampus and cerebellum were dissected and homogenized in $\mathrm{KCl} 1.5 \%$ with manual homogenizer and stored in a freezer $\left(-20^{\circ} \mathrm{C}\right)$ until analysis.

\section{Open field test}

The animals were individually placed in a $20 \mathrm{~cm} \times 30 \mathrm{~cm} \times 50 \mathrm{~cm}$ wooden box divided in 12squares by lines painted on its floor. Behavioral analyzes were performed in a quiet room during $5 \mathrm{~min}$ and the number of the squares crossed with the four paws, number of rearing responses, number of grooming and number of fecal boli were recorded by an observer not aware of the subject condition. ${ }^{22}$ Crossing and rearing are considered exploratory behavior, while grooming and fecal boli are considered expressions of emotion..$^{23}$ The number of squares crossed is indicative of motor activity and its reduction along the session, a measure of habituation. ${ }^{22}$ Higher levels of anxiety should lead to a decrease in the number of squares visited in center. The reduction in the number and in the time of rearing responses along the session is also considered a measure of habituation. This test was performed subsequent to the period of gestation and lactation of Wistar rats.

\section{The elevated plus maze test}

The animals were placed individually in the apparatus for the elevated plus maze test, as described by Walf $\&$ Frye. ${ }^{24}$ This apparatus consists of two open arms $(10 \mathrm{X} 50 \mathrm{~cm})$, no bulkhead, arranged in opposition to one another and two enclosed arms $(50 \mathrm{X} 10 \mathrm{X} 40 \mathrm{~cm})$, and also opposed forming a cross. This cross is mounted on wood, on top of an elevated base $50 \mathrm{~cm}$ high. The animal was first placed on the center of the apparatus, with the head turned to the closed arm, their movements being evaluated by a trained examiner for 5 minutes. The parameters considered were latency time parameters, amount of fecal boli, time spent in the open arm and closed arm. Between the exposure of another animal, the cleaning apparatus was performed. This test was performed subsequent to the period of gestation and lactation of Wistar rats. 


\section{Thiobarbituric acid reactive substances (TBARS) measurement}

TBARS were used to determine lipid peroxidation and were measured according to the method described by Ohkawa et al. ${ }^{25}$ In short, $50 \mu \mathrm{L}$ of $8.1 \%$ sodium dodecyl sulfate (SDS), $375 \mu \mathrm{L}$ of $20 \%$ acetic acid (pH 3.5), and $375 \mu \mathrm{L}$ of $0.8 \%$ TBA were added to $200 \mu \mathrm{L}$ of homogenates and then incubated in boiling water bath for $60 \mathrm{~min}$. After cooling, the mixture was centrifuged $(1,000 \mathrm{~g} / 10 \mathrm{~min})$. The supernatant was removed and the absorbance was read at $535 \mathrm{~nm}$ on a spectrophotometer (T80 UV/VIS Spectrometer, PG Instruments). Commercially available malondialdehyde was used as a standard. Results were expressed as nmol/mg protein.

\section{Carbonyl assay}

Carbonyl assay was used to determine oxidative damage to proteins. Homogenates were incubated with 2.4 dinitrophenylhydrazine (DNPH $10 \mathrm{mmol} / \mathrm{L}$ ) in $2.5 \mathrm{~mol} / \mathrm{L} \mathrm{HCl}$ solution for $1 \mathrm{~h}$ at room temperature, in the dark. Samples were vortexed every $15 \mathrm{~min}$. Then $20 \%$ TCA (w/v) solution was added in tube samples, left in ice for $10 \mathrm{~min}$ and centrifuged for $5 \mathrm{~min}$ at $1,000 \mathrm{~g}$, to collect protein precipitates. Another wash was performed with $10 \%$ TCA. The pellet was washed three times with ethanol: ethyl acetate $(1: 1)(\mathrm{v} / \mathrm{v})$. The final precipitates were dissolved in $6 \mathrm{~mol} / \mathrm{L}$ guanidine hydrochloride solution, left for $10 \mathrm{~min}$ at $37{ }^{\circ} \mathrm{C}$, and read at $360 \mathrm{~nm}$ (T80 UV/VIS Spectrometer, PG Instruments). ${ }^{26}$ The results were expressed as nmol/ mg protein.

\section{Sulfhydryl assay}

This assay is based on the reduction of 5.50-dithio-bis (2nitrobenzoic acid) (DTNB) by thiols, generating a yellow derivative (TNB) whose absorption is measured with a spectrophotometer at $412 \mathrm{~nm} .{ }^{27} \mathrm{In}$ short, $0.1 \mathrm{mM}$ DTNB was added to $120 \mu \mathrm{L}$ of the samples, followed by a30-min incubation at room temperature in a dark room. Absorption was measured at $412 \mathrm{~nm}$ (T80 UV/VIS Spectrometer, PG Instruments). The sulfhydryl content is inversely correlated to oxidative damage to proteins. Results were reported as $\mathrm{nmol} / \mathrm{mg}$ protein.

\section{Determination of antioxidant enzyme activities}

SOD activity, expressed as USOD/mg protein was based on the inhibition of the ratio of autocatalytic adrenochrome formation at 480nm (T80 UV/VIS Spectrometer, PG Instruments). ${ }^{28}$ CAT activity was determined by following the decrease in $240 \mathrm{~nm}$ absorption of H2O2 (T80 UV/VIS Spectrometer, PG Instruments). It was expressed as $\mathrm{UCAT} / \mathrm{mg}$ protein. ${ }^{29}$

\section{Protein determination}

Protein concentrations were determined by the method of Lowry, Rosebrouh, Lewis-Farr and Randall [30] using bovine serum albumin as standard.

\section{Statistical analysis}

Results were expressed as mean and standard error of the mean, and the normality of the data was assessed by the Kolmogorov-Smirnov test, checking normal distribution of data. Differences between groups were analyzed using two-way ANOVA (factor group and factor gavage), followed by post Holm-Sidak-test, with $\mathrm{p}<0.05$ considered significant. All analyzes were performed using the statistical softwares
SPSS version 17.0 (International Business Machines Corporation, New York, NY) and SigmaStat (Jandel Scientific Software, San Jose, CA, USA).

\section{Results and discussion}

According to the Brazilian legislation, grape juice is a product made from $100 \%$ grape, which preserves color, scent and taste of the grape used. In order to understand the juice composition, the chemical composition was assessed and the following parameters were evaluated: total acidity, volatile acidity in acetic acid, total sugars, and relative density at $20 \mathrm{oC}$, alcoholic degree, $\mathrm{pH}$, benzoic acid and sorbic acid (Table 1).

Table I Chemical composition, of red grape juice Vitis labrusca. Values are expressed as meantstandard deviation

\begin{tabular}{|c|c|c|}
\hline Analysis & Mean & SD \\
\hline Total Acidity (g\% Tartaric acid) & 0.70 & 0.00 \\
\hline Volatile acidity as acetic acid (g/l00g) & 0.02 & 0.00 \\
\hline Total Sugars $(\mathrm{g} / \mathrm{I} 00 \mathrm{~mL})$ & 17.4 & 0.00 \\
\hline Relative density at $20^{\circ} \mathrm{C}$ ) & 1.07 & 0.0001 \\
\hline Alcoholic Degree (\%v/v) & 0.3 & 0.00 \\
\hline $\mathrm{pH}$ & 3.49 & 0.01 \\
\hline Benzoic acid (mg/L) & 0.00 & 0.00 \\
\hline Sorbic acid (mg/L) & 0.00 & 0.00 \\
\hline
\end{tabular}

In regards to the behavioral analysis, the Test of Open Field demonstrated that purple grape juice by gavage was able to increase the latency time, decrease the time of rearing and decrease the time and the frequency of central ambulation (Figure 1). There are no differences in the other parameters showed no changes. In the elevated plus maze test, the grape juice administered either by gavage or free access was able to decrease the time spent in open arm, other parameters are not changed (Figure 2). It is known that these tests can be used to evaluate the effect of substances and food in the animal behavior. The operation of the apparatus in the open field test was checked through parameters such as rearing and ambulation of the animal, while the emotional state was interpreted through the number of fecal boli and grooming. ${ }^{22}$ Our results showed that the chronic treatment with purple grape juice, variety Bordo (Vitis labrusca), by gavage, during the gestational period in this study, showed the ability to increase the latency time, decrease the time of rearing and decrease the time and the frequency of central ambulation in Wistar rats in the Open Field Test. These results suggested that the grape juice consumption by gavage, what is a stress factor, can reduce the exploratory behavior induced. Soares et al. ${ }^{31}$ showed that one dose of grape juice consumption by mices 24 hours after being subjected to $\mathrm{X}$-ray provoke a reduction in the latency time. ${ }^{31}$ Another study found that the mate (Ilex paraguariensis A. St. -Hil) was able to increase the exploration behavior in rats and, thus, this tea left them more active. ${ }^{32}$ This change in behavior was attributed to the high concentration of caffeine found in mate. ${ }^{32}$ Until this moment, there aren't other studies involving gestational model and grape, and or their derivatives. 


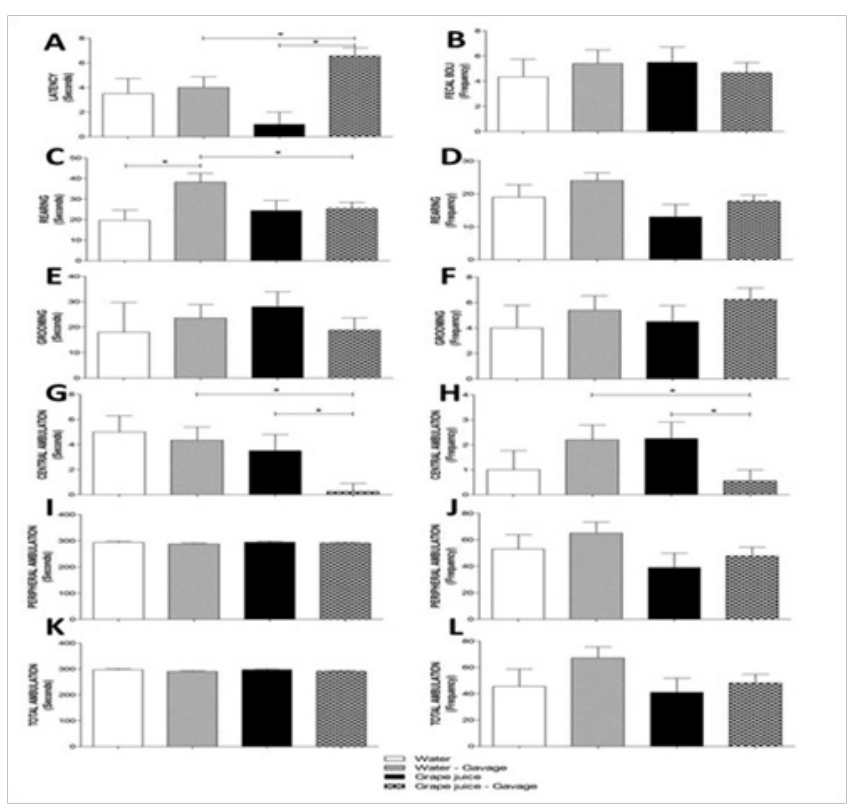

Figure I Behavioral parameters evaluated by the Test of Open Field: Latency (seconds) (A); fecal boli (frequency) (B); Rearing (seconds) (C); Rearing (frequency) (D); Grooming (seconds) (E); Grooming (frequency) (F); Central Ambulation (seconds) (G); Central Ambulation (frequency) (H); Peripheral Ambulation (seconds) (I); Peripheral Ambulation (frequency) (J); Total Ambulation (seconds) (K); Total Ambulation (frequency) (L) in Wister rats, after the period of lactation, treated with red grape juice expressed as mean \pm SEM. * Statistically significant difference $(p<0.05)$ by two-way ANOVA, with post-test Holm-Sidak .

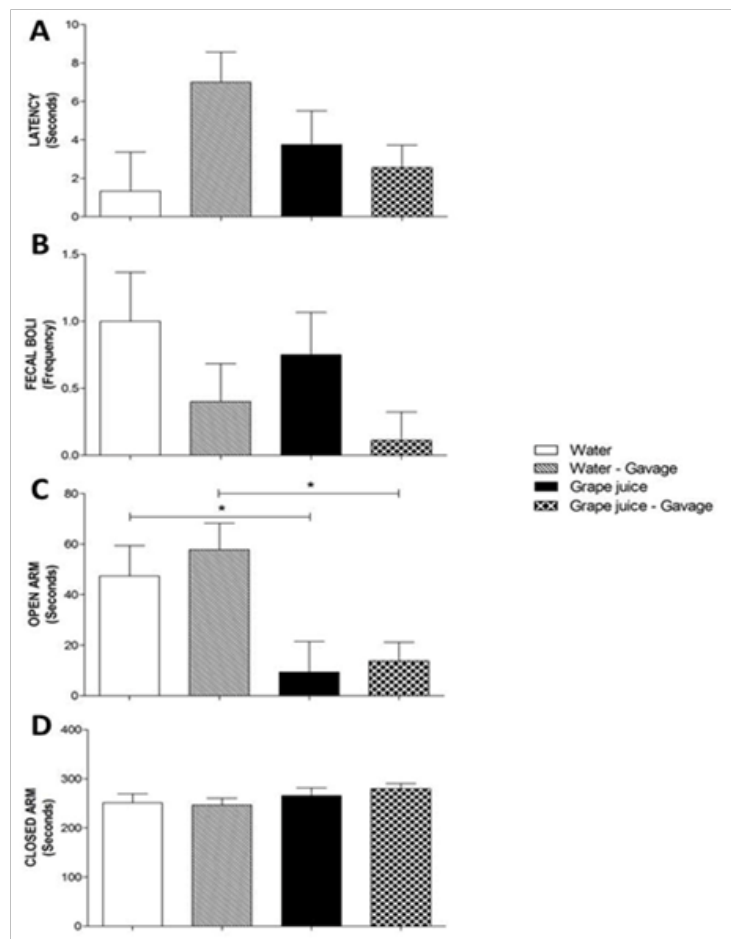

Figure 2 Behavioral parameters evaluated by Test elevated plus-maze: Latency (seconds) (A); fecal boli (frequency) (B); Open Arm (seconds) (C); Closed Arm (seconds) (D) in Wistar rats, after the period of lactation, treated with red grape juice expressed as mean \pm SEM. *Statistically significant difference $(p<0.05)$ by two-way ANOVA, with post-test Holm-Sidak.
In the Open Field test, it is also possible to evaluate the emotional status through the amount of fecal boli. In our experiment, the animals treated with grape juice showed no significant difference between the groups. The same was found in other study of our group. ${ }^{33}$ Our study is the first study to show this experimental design and this result. The elevated plus maze test is a test for anxiety, it is possible to verify the behavior of the animals in an adverse environment (open arm) and a protected environment (closed arm). ${ }^{34}$ We found that the grape juice, by gavage and free access, was able to reduce the stay time of animals in the open arm of the elevated plus maze test, when compared to the group treated with water (both administration ways), which may indicate an attitude of fear in the face of an area considered unprotected by the animal.

In our experiment, we found that the stress caused by gavage was crucial to the achievement of results in the females. Some studies in the literature show that the constant stress can be decisive for the fetal development of the offspring. The exacerbated stress could cause congenital malformation and reduce the development of the embryo and fetus. ${ }^{35,36}$ Another study also demonstrated that the gestational stress could influence with negative consequences for the mother and for the offspring, changing, for example, the ingestion of food and cortisol levels. ${ }^{37}$ We observed that the gestational stress, in our model induced by gavage, was able to influence the levels of TBARS in three tissues; the levels of Carbonyl, SOD and the ratio SOD/CAT in the hippocampus and the cerebellum; as well as the levels of CAT in the hippocampus and sulfhydryl levels in cerebral cortex (Figures 3) (Figure 4).

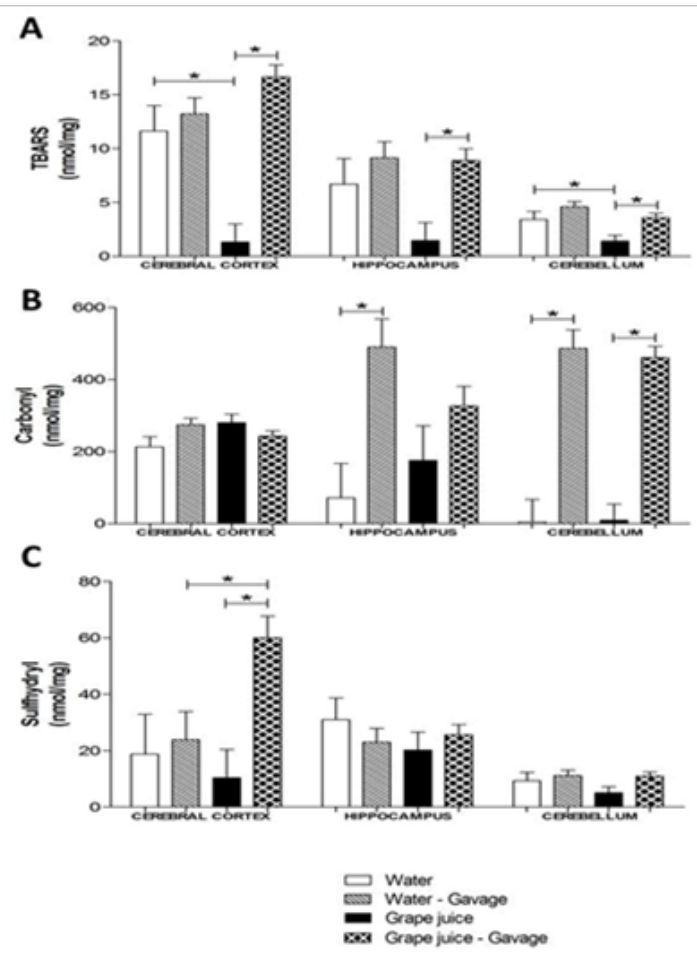

Figure 3 Levels of TBARS (nmol/mg) (A); Carbonyl (nmol/mg) (B) and Sulfidrilas $(\mathrm{nmol} / \mathrm{mg}$ ) (C) expressed as mean \pm EPM in cerebral cortex, hippocampus and cerebellum of Wistar rats, after the period of lactation, treated with red grape juice. * Statistically significant difference according to analysis of variance two-way ANOVA, followed by post-test of Holm-Sidak $(p<0.05)$. 


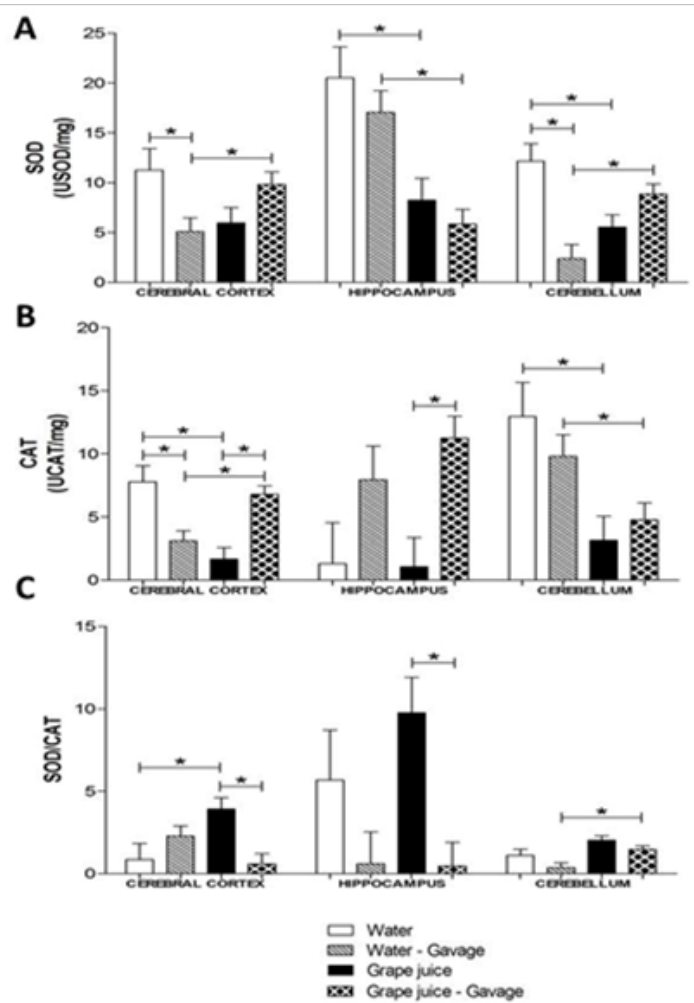

Figure 4 Activity of superoxide dismutase (SOD) (USOD/mg) (A); activity of catalase (CAT) (UCAT/mg) (B) and SOD/CAT (C) expressed as mean \pm EPM in cerebral cortex, hippocampus and cerebellum of Wistar rats, after the period of lactation, treated with red grape juice. * Statistically significant difference according to analysis of variance two-way ANOVA, followed by post-test of Holm-Sidak $(p<0.05)$.

It is known that hormonal changes occurring during pregnancy induce changes in lipid metabolism and consequently are accompanied by significant variations in oxidant/antioxidant status. ${ }^{38,39} \mathrm{We}$ observed that in the three tissues evaluated the gavage was an inducer of damage, increasing the TBARS levels, when compared with the group treated free access (Figure 3A). However, the grape juice, consumed by free access, reduced the TBARS levels in cerebral cortex, hippocampus and cerebellum $(\mathrm{p}=0.000 ; \mathrm{p}=0.002 ; \mathrm{p}=0.006)$ (Figure 3A). As well as in our experiment, Dani et al., ${ }^{4}$ showed that the grape juice promoted a TBARS levels reduction in substantia nigra and striatum of rats. ${ }^{4}$ Our data are also corroborated by another study conducted by Bubols et al., ${ }^{15}$ where a diet with foods rich in polyphenols reduced the levels of lipid peroxidation in serum of pregnant ewes. ${ }^{15}$ In an in vitro study conducted with extract of Vitis labrusca grapevine leaves, $\mathrm{H}_{2} \mathrm{O}_{2}$ as inducer of damage, the grape leave extract promotes a lipid peroxidation reduction in hippocampus and cerebellum, not demonstrating changes in the cerebral cortex of male Wistar rats, 10days of age.?

To assess the oxidative damage to proteins we performed the technique of protein oxidation (Carbonyl assay). ${ }^{26}$ We observed that the gavage was the main factor that influenced the levels of carbonyl protein in the hippocampus and cerebellum (Figure 3B). The effect of foods rich in polyphenols consumption on the oxidative damage to proteins appears to be ambiguous in the literature. A study conducted with pregnant rats, treated with vitamin A, evidenced an increase in carbonyl protein levels in hippocampus and striatum. ${ }^{40}$ The same result was observed in a study with pregnant ewes submitted to a diet supplemented with foods rich in polyphenols but in serum. ${ }^{15}$ This fact could be explained by the fact that when in high doses, the polyphenols may present pro-oxidant action..$^{41-43}$ However, other studies show the benefit of consumption of products rich in polyphenols, such as grape juice. ${ }^{3,4,7,9,44,45}$ The reduction of oxidative damage by consumption of these products was observed in pregnancy model, where the consumption of seed extract of Euterpe oleracea Mart. (Acai) reduced levels of carbonyl protein in plasma and kidney of female rats fed pregnant fed with a hypoprotein $\operatorname{diet}^{46}$

Among the antioxidant defenses, the thiol groups stand out (-SH). Thiols groups are defined as a class of derivatives of organic sulfur characterized by the presence of sulfhydryl residues. In biological systems, the SH has several functions, among them a central role in the coordination of the network of this defense system. ${ }^{47}$ The sulfhydryl technique was used to evaluate the not enzymatic defenses. Thus, we verified that the gavage was the determining factor for changing levels of sulfhydryl only in the cerebral cortex in the grape juice groups and the highest value is observed in the grape juice consumed by gavage $(\mathrm{p}=0.013$ ) (Figure 3C). When compared to animals treated with water or grape juice, by gavage, it was observed that the grape juice was able to increase the levels of biosynthesis in the cerebral cortex of these animals. Our data corroborate with studies conducted with different natural compounds, such as grape juice, propolis and soy protein, where in all the studies, it was observed an increase in the thiol groups (-SH) after the treatment in question. ${ }^{44,48,49}$ However, a study conducted by Bubols et al., ${ }^{15}$ evidenced a decrease in levels of thiol groups in serum of pregnant ewes submitted to a diet supplemented with foods rich in polyphenols, showing that, when in high doses, the polyphenols may present pro-oxidant action. ${ }^{15,41-43}$ The cells have several antioxidant enzymes, including SOD, CAT, GPx, and GST to prevent the reactive species of oxygen damage. ${ }^{50}$ In our study, we evaluated the SOD and CAT enzymatic activities.

As the enzymatic activity of SOD, we observed that the main factor for changing the levels of SOD, in the cerebral cortex, hippocampus and cerebellum, was the gavage factor (Figure 4A). We observed that in the water groups, the gavage reduced the SOD activity in cerebral cortex and cerebellum; however this decrease was prevented by the grape juice consumption (Figure 4A). The increase of this enzyme in the cerebral cortex and the cerebellum was observed in another study with extract of leaves of grapevine Vitis labrusca in Wistar rats. ${ }^{9}$ The similar behavior of the enzyme SOD under the same structures can explain that different tissues may contain varying amounts of enzymes and, therefore, behave in many ways due to differences in blood supply in each of regions of the brain. ${ }^{51}$ The increase in the activity of SOD was also evidenced in the study of Takayama et al., ${ }^{52}$ carried out with leaves of Vitis coignetiae Pulliat, in plasma of rats with not alcoholic hepatic steatosis. ${ }^{52}$ The decrease in enzyme yet, activity observed in our study in the hippocampus corroborates the in vitro experiment performed with extracts from grapevine leaves of Vitis labrusca, organic and conventional, and $\mathrm{H} 2 \mathrm{O} 2$ as inducer of oxidative damage on kidney and heart. ${ }^{45}$ In the cerebellum of rats treated by free access, it was observed that grape juice was also able to decrease the enzymatic activity of SOD when compared with the water group ( $\mathrm{p}=0.010)$ (Figure 4A).

As the enzymatic activity of the CAT, we observed that in the hippocampus, the main factor that altered levels of the enzyme CAT 
was the gavage. On the contrary, in the cerebellum, the determining factor for change in these levels was the factor group, i.e. if the animal received water or grape juice during the treatment (Figure 4B). In this case, the grape juice was able to decrease the CAT levels in this tissue (Figure 4B). However, in the cerebral cortex, we observed that the gavage has promoted a decrease in the activity of the enzyme in water group $(p=0.007)$. This reduction can also be observed when the groups treated by free access were evaluated, where the same was caused by grape juice $(p=0.001)$. Still in the cerebral cortex, in groups treated by gavage, the grape juice was able to increase the activity of the enzyme in question $(p=0.003)$. Yet in the cerebellum, we found that the determining factor was the consumption, because in both groups (free access and gavage), the grape juice was able to reduce the levels of enzyme activity in question ( $\mathrm{p}=0.001$ ) (Figure 4B). This decrease caused by grape juice observed in our study in the cerebral cortex and the cerebellum, was also evidenced in another previous study, in which male Wistar rats were submitted to intraperitoneal injections of grapevine leaf extract of Vitis labrusca. ${ }^{9}$ In the hippocampus, it was possible to observe that the gavage was an important factor for the increase in activity of the CAT enzyme when compared with the groups treated with juice, i.e. the grape juice was not able to contain the increase in the activity of the enzyme in question caused by gavage $(p=0.014)$. On the contrary, a study showed the reduction of enzyme CAT in striatum of pregnant rats treated with vitamin A. ${ }^{40}$ SOD and CAT enzymes are the first line of defense against free radicals, the balance between them is very important. For this reason, the determination of the ratio SOD/CAT is of extreme importance. ${ }^{53}$

This imbalance between the SOD and CAT shows that the gavage may have been one of the factors in the induction of damage, observed through the technique of TBARS and Carbonyl. In the cerebral cortex, we found that the gavage was able to decrease the values of SOD/ CAT in animals treated with grape juice $(\mathrm{p}=0.004)$ (Figure $4 C)$. This decrease was also observed by Dani et al., ${ }^{4}$ and Wohlenberg et al., ${ }^{9}$ studies with purple grape juice (organic and conventional) and the organic grape leaves extract of Vitis labrusca, were able to prevent the increase caused by $\mathrm{CCl} 4$ in different tissues of the central nervous system. ${ }^{4,9}$ On the other hand, when animals treated by free access were evaluated, the grape juice was able to increase the values of SOD/ CAT in the cerebral cortex of these animals when compared to the group treated with water $(p=0.024)$. However, in the hippocampus, we observed that the main factor for change in this respect was the factor gavage. Thus, we observed in the animals treated by free access that the grape juice provoked an increase in SOD/CAT. This demonstrates that the gavage was able to decrease the proportion of this ratio being evidenced by the fact that it was able to increase lipid peroxidation. Yet, in the cerebellum, factors, group and gavage, were able to cause effects on the relationship, because the grape juice administrated by gavage increased the ratio SOD/CAT when compared with animals treated with water $(\mathrm{p}=0.012)$ (Figure $4 \mathrm{C})$.

In general, in the cerebellum, the juice was able to increase this ratio. The opposite was observed in this tissue when evaluated TBARS technique can thus affirm that the increase in the ratio between the enzymatic defenses are protecting against oxidative damage to lipids. Our data corroborate with the findings of another study which also evidenced an increase in the ratio SOD/CAT by vitamin A in tissues of the central nervous system of pregnant rats. ${ }^{40}$

\section{Conclusion}

We can conclude that the gestational stress is an important factor for changing various parameters, behavioral or biochemical. In our study, the main stress factor was the handling of the animals that is the gavage. However, we note that grape juice was able to improve some parameters of the response of the cerebral structure facing the stresses caused by gavages. Then, we could conclude that grape juice is a food source important for consumption during pregnancy, as it can promote various benefits to the health of this population. From this, we suggest further studies to elucidate the mechanism involved between brain structures, oxidative stress and pregnancy.

\section{Acknowledgements}

We thank the Methodist University Center IPA, the CAPES, the IBRAVIN, FAPERGS and to CNPq for the financial support of this work.

\section{References}

1. http://www.uvibra.com.br/pdf/safra_uva2002-2011.pdf.

2. Dani C, Oliboni LS, Bonatto D, et al. Phenolic content and antioxidant activities of white and purple juices manufactured with organicallyproduced grapes. Food Chem Toxicol. 2007;45(12):2574-2580.

3. Dani C, Oliboni LS, Pasquali MA, et al. Intake of purple grape juice as a hepatoprotective agent in Wistar rats. J Med Food. 2008;11(1):127-132.

4. Dani C, Pasquali MA, Oliveira MR, et al. Protective effects of purple grape juice on carbon tetrachloride-induced oxidative stress in brains of adult Wistar rats. J Med Food. 2008;11(1):55-61.

5. Romero-Pérez AI, Ibern-Gómez M, Lamuela-Raventós RM, et al. Piceid, the major resveratrol derivative in grape juice. J Agric Food Chem. 1999;47(4):1533-1536.

6. Krikorian R, Nash TA, Shidler MD, et al. Concord grape juice supplementation improves memory function in older adults with mild cognitive impairment. Br J Nutr. 2010;103(5):730-734.

7. Dani C, Oliboni LS, Agostini F, et al. Phenolic content of grapevine leaves (Vitis labrusca var. Bordo) and its neuroprotective effect against peroxide damage. Toxicol In Vitro. 2010;24(1):148-153.

8. Rodrigues AD, Scheffel TB, Scola G, et al. Neuroprotective and anticonvulsant effects of organic and conventional purple grape juices on seizures in Wistar rats induced by pentylenetetrazole, Neurochem Int. 2012;69(8):799-805

9. Wohlenberg M, Almeida D, Bokowski L, et al. Antioxidant activity of grapevine leaf extracts against oxidative stress induced by carbon tetrachloride in cerebral cortex, hippocampus and cerebellum of Rats. Antioxidants. 2014;3(2):200-211.

10. Andorn AC, Britton RS, Bacon BR. Evidence that lipid peroxidation and total iron are increased in Alzheimer's brain. Neurobiol Aging. 1990;11(3):316.

11. Bauer V, Bauer F. Reactive oxygen species as mediators of tissue protection and injury. Gen Physiol Biophys. 1999;18:7-14.

12. Moosmann B, Behl C. Antioxidants as treatment for neurodegenerative disorders. Expert Opin Investig Drugs 2002;11(10):1407-1435.

13. Sun AY, Simonyi A, Sun G. The "French Paradox" and beyond: neuroprotective effects of polyphenols. Free Radic Biol Med. 2002;32(4):314-318

14. Arola-Arnal A, Oms-Oliu G, Crescenti A, et al. Distribution of grape seed flavanols and their metabolites in pregnant rats and their fetuses. Mol Nutr Food Res. 2013;57(10):1741-1752.

15. Bubols GB, Zielinski P, Piccoli Jr AL, et al. Nitric oxide and reactive species are modulated in the polyphenol-induced ductus arteriosus constriction in pregnant sheep. Prenat Diag. 2014;34(13):01-09. 
16. Zielinski P, Piccoli Jr AL, Manica JL, et al. New insights on fetal ductal constriction: role of maternal ingestion of polyphenol-rich foods. Expert Rev Cardiovasc Ther. 2010;8(2):291-298.

17. Zielinsky P1, Piccoli AL Jr, Manica JL, et al. Maternal consumption of polyphenol-rich foods in late pregnancy and fetal ductus arteriosus flow dynamics. J Perinatol. 2010;30(1):17-21.

18. Wohlenberg MF, Gonçalves LK, Schaffer TK, et al. Effect of grape juice on some biochemical and oxidative stress parameters in serum and liver enzymes of pregnant and lactating rats. IBSPR. 2015;3(4):37-46.

19. Official Methods of Analysis of AOAC International. Association of Official Analytical Chemists. 18th ed. M.D. Gaithersburg; 2005.

20. Singleton VL, Orthofer R, Lamuela-Raventós RM. Methods in Enzymology. San Diego: Academic Press; 1999. p. 159-178.

21. Lamuela-Raventos RM, Waterhouse AL. Occurrence of resveratrol in selected California wines by a new HPLC method. J Agric Food Chem. 1993;41(4):521-523.

22. Walsh RN, Cummins RA. The open -field test: a critical review. Psychol Bull. 1976;83:482-504.

23. Archer J. Tests for emotionality in rats and mice: The review. Ann Behav Med. 1973;21(2):205-235.

24. Walf AA, Frye CA. The use elevated plus maze as an assay of anxietyrelated behavior in rodents. Nat Protoc. 2007;2:322-328.

25. Ohkawa H, Ohishi N, Yagi K. Assay for lipid peroxides in animal tissues by thiobarbituric acid reaction. Anal Biochem. 1979;95(2):351-358.

26. Levine RL, Williams JA, Stadtman ER, et al. Carbonyl assay for determination of oxidatively modified proteins. Method Enzymol. 1994;233:357-363.

27. Arksenov MY, Markesberry WR. Change in thiol content and expression of glutathione redox system gene in the hippocampus and cerebellum in Alzheimer's disease. Neurosci Lett. 2001;302(2-3):141-145.

28. Bannister JV, Calabrese L. Assays for SOD. Methods Biochem Anal. 1987;32:279-312.

29. Aebi H. Catalase in vitro. Method Enzymol. 1984;105:121-126.

30. Lowry $\mathrm{OH}$, Rosebrouh NJ, Lewis-Farr AL, et al. Protein measurement with the Folin phenol reagent. J Biol Chem. 1951;193(1):265-275.

31. Soares FA, Dalla Corte C, Andrade E, et al. Purple grape juice as a protector against acute $\mathrm{X}$-irradiation induced on mobility, anxiety, and feeding behavior in mice. Nutr Hosp. 2014;29(4):812-821.

32. Castaldelli APA, Vieira PL, Przygodda F, et al. Effect of mate (Ilex paraguariensis A. St. -Hil.) on the behavior and physiology of Wistar rats. Rev Bras Bioc. 2011;9:514-519.

33. Gabardo T, Peripolli CM, de Andrade RB, et al. Assessment of changes in energy metabolism parameters provoked by carbon tetrachloride in Wistar rats and the protective effect of white grape juice. Toxicol Rep. 2015;2:645-653.

34. Nin MS, Caletti G, Schneider Jr R, et al. Neurociências: Modelos Experimentais em Animais. 1st ed. EdiPUCRS, Porto Alegre, Brazil; 2014. p. $107-120$.

35. Agarwal A, Allamaneni SS. Role of free radicals in female reproductive diseases and assisted reproduction. Reprod Biomed Online. 2004;9(3):338-347.

36. Guérin P, El Mouatassim S, Ménézo Y. Oxidative stress and protection against reactive oxygen species in the pre-implantation embryo and its surroundings. Hum Reprod Update. 2001;7(2):175-189.
37. Amugongo Sk, Hlusko L. Impact of prenatal stress on growth of the offspring. Aging Dis. 2014;5(1):1-16.

38. Bukhari S, Rajoka M, Ibrahim Z, et al. Oxidative stress elevated DNA damage and homocysteine level in normal pregnant women in the segment of Pakistani population. Mol Biol Rep. 2011;38(4):2703-2710.

39. Loy S, Kns S, Jm H. Increased in maternal adiposity and poor lipid profile is associated with oxidative stress markers during pregnancy. Prev Med. 2013;57:S41-S44.

40. Schnorr EC, Morrone MS, Simões-Pires A, et al. Vitamin A supplementation in rats under pregnancy and nursing induces behavioral changes and oxidative stress upon striatum and hippocampus of dams and their offspring. Brain Res. 2011;1369:60-73.

41. Decker E. Phenolics: prooxidants or antioxidants? Nutr Rev. 1997;55(11):396-398.

42. Raza H, John A. Green tea polyphenol epigallocatechin-3-gallate differentially modulates oxidative stress in PC12 cell compartments. Toxicol Appl Pharm. 2005;207:212-220.

43. Watjen W, Michels G, Steffan B, et al. Low concentrations of flavonoids are protective in rat H4IIE cells whereas high concentrations cause DNA damage and apoptosis. $J$ Nutr. 2005;135(3):525-531.

44. Buchner I, Medeiros N, Lacerda D, et al. Hepatoprotective and antioxidant potential of organic and conventional grape juices in rats fed a high-fat diet. Antioxidants. 2014;3:323-338.

45. Oliboni L, Dani C, Funchal C, et al. Hepatoprotective, cardioprotective, and renal-protective effects of organic and conventional grapevine leaf extracts (Vitis labrusca var. Bordo) on rats' tissues. Ann Braz Acad Sci. 2011;83:1403-1411.

46. De Bem G, Costa C, Oliveira P, et al. Protective effect of Euterpe oleracea Mart (acai) extract on programmed changes in the adult rat offspring caused by maternal protein restriction during pregnancy. $J$ Pharm Pharmacol. 2014;66(9):1328-1338.

47. Zugno AI, Stefanello FM, Scherer EBS, et al. Guanidinoacetate decreases antioxidant defenses and total protein sulfhydryl content in striatum of rats. Neurochem Res. 2008;33(9):1804-1810.

48. Capucho C, Sette R, Predes FS, et al. Green Brazilian propolis effects on sperm count and epididymis morphology and oxidative stress. Food Chem Toxicol. 2012;50(11):3956-3962.

49. Ruan Q, Chen Y, Kong X, et al. Heat-induced aggregation and sulphydryl/disulphide reaction products of soy protein with different sulphydryl contents. Food Chem. 2014;156:14-22.

50. Pari L, Suresh A. Effect of grape (Vitis vinifera L.) leaf extract on alcohol induced oxidative stress in rats. Food Chem Toxicol. 2008;46(5):1627-1634.

51. Erecinska M, Silver IA. Advances in Neurology: Cellular and Molecular Mechanism of Ischemic Brain Damage. Philadelphia: Lippincott Raven Publishers; 1996. p. 119-131.

52. Takayama F, Nakamoto K, Kawasaki H, et al. Beneficial effects of Vitis coignetiae Pulliat leaves on nonalcoholic steatohepatitis in a rat model. Acta Med. 2009;63(2):105-111.

53. Dal-Pizzol F, Klamt F, Benfato MS, et al. Retinol supplementation induces oxidative stress and modulates antioxidant enzyme activities in rat Sertoli cells. Free Radic Res. 2001;34:395-404. 